\title{
Seismic Behavior of Hybrid Coupled Wall System
}

\author{
Thavera Wihardja $\mathrm{a}^{*}$, Iswandi Imran ${ }^{2 *}$ \\ ${ }^{1}$ Departement of Civil Engineering, Parahyangan Catholic University, Bandung-40141, Indonesia \\ ${ }^{2}$ Faculty of Civil and Enviromental Engineering, Bandung Institute of Technology, Bandung-40132, Indonesia \\ *Corresponding author: thawihardja@hotmail.com,iswandiimran@gmail.com
}

\begin{abstract}
Reinforced concrete (RC) couple wall systems, where RC beams couple two or more RC walls in series, are frequently used in high-rise buildings. Generally, coupling beams are made of RC materials. Steel coupling beam is an alternative for RC coupling beam which has a complex and and unefficient detailing construction. This paper presents a study on the use of Hybrid Coupled Wall System (HCWS) in seismic resistant high-rise RC structures. In the study, 25 storey office buildings with three types of coupling beams and three types of walls distributed over the height of the structure and located in a region with high seismicity are designed. Applying a performance-based design approach, this study developed an efficient design for RC structures having Coupling Ratio (CR) values $64.55 \%$ and affect the behavior of the wall pier in the upper region of the structure where widespread plastification and earlier crushing failure happen. Based on this findings, steel coupling beams can be used as an alternative with statisfying all performance criteria and perform at Life Safety(LS).
\end{abstract}

Keywords-Hybrid Coupled Wall System, Steel Coupling Beam, Coupling Ratio.

\section{INTRODUCTION}

$\mathrm{R}$ einforced concrete (RC) coupled wall system, where

$\mathrm{RC}$ beams coupled two or more RC walls in series, are frequently used in high-rise construction. The benefit of coupling in such systems are well recognized and well understood. The coupling beams provide transfer of vertical forces beetwen adjacent walls, which creates a frame-like coupling action that resists portion of the total overturning moment induced by the seismic action. Coupling action can reduce the moment that must be resist by the individual wall piers, provides a means by which seismic energy dissipated over the entire height of the wall system as the coupling beams underego inelastic deformations, and increase a lateral stiffness coupled wall system where significantly greater than the sum of its component wall pier permiting a reduced footprint for the load resisting system.

Coupled wall system failure mechanism effected by strength, stiffness, and energy dissipated. Reinforcement detailing in join region has effected energy dissipated proces. Energy dissipated in the system expected to be happens in join region between coupling beam and wall, which could be inelastic shear distortion or plastic hinge rotation. Preliminary structure system was designed for failure mechanism with plastic hinge rotation. The degradation of shear resisting mehanism attribute to concrete under load reversals, has led the designer to provide special diagonal reinforcement complicated erection, potentially incressing both construction time and cost. To mitigate these problems, hybrid coupled wall system with steel coupling beams can be used as an alternative to reinforced concrete beams. The resulting structural system is referred to as hybrid coupled wall system (HCWS) and is the subject of this study.

\section{STRUCTURE SYSTEM ANALYSIS METHOD}

This paper present a design structure using mathematic models for office building where located in Jakarta (Site Class D) and belong to KDS-D. Coupled wall structure system designed with a special reinforced concrete shear wall system. Structure consist of 25 storey with $3.5 \mathrm{~m}$ height for each story and total height structure is $87.5 \mathrm{~m}$. Both wide and long of the structure is $24 \mathrm{~m}$. Structure system composed by three type of coupling beams and three type of walls distributed over the height of the structure (Figure 1).

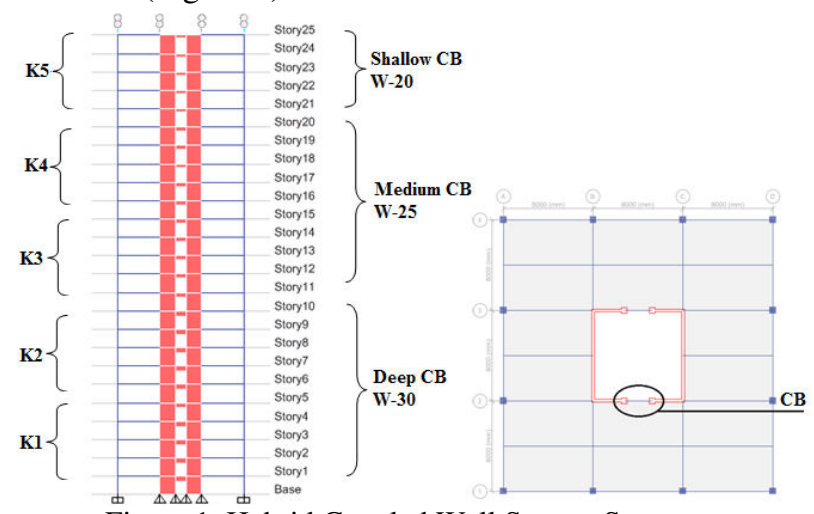

Figure 1. Hybrid Coupled Wall System Structure

\section{A. Coupling Ratio}

Research over the half past century on coupled wall systems has shown that their strucutural performance is strongly influenced by the amount of coupling provided by the system. Although the majority of studies have focused on reinforced concrete systems, the system behavior and mechanics are the same for all coupled wall structures including hybrid systems. Indeed, the behavior itself is a manifestation of the classic dowelled cantilever problem describe by Chitty (1947). Figure 2 shows a coupled wall system deformed under the influence of 
laterla loads, which cause a system overturning moment, OTM. In response to the applied loading, a coupling beams (j), develops end moments (not shown in the figure $)$ and coresponding shears $\left(\mathrm{V}_{\text {beam,j }}\right)$. The coupled system resist OTM through the development of an axial force couple $\left(\mathrm{V}_{\text {beam,j }}\right.$ over the lever arm $\left.\mathrm{L}\right)$, resulting from the accumulation of the beam shears, as well as flexural reactions in the individual wall piers ( $\mathrm{m} 1$ and $\mathrm{m} 2$ ). Base shear is resisted by shear reactions at the bases of the wall piers. The proportion of OTM resisted by the couple is defined as the Coupling Ratio (CR).

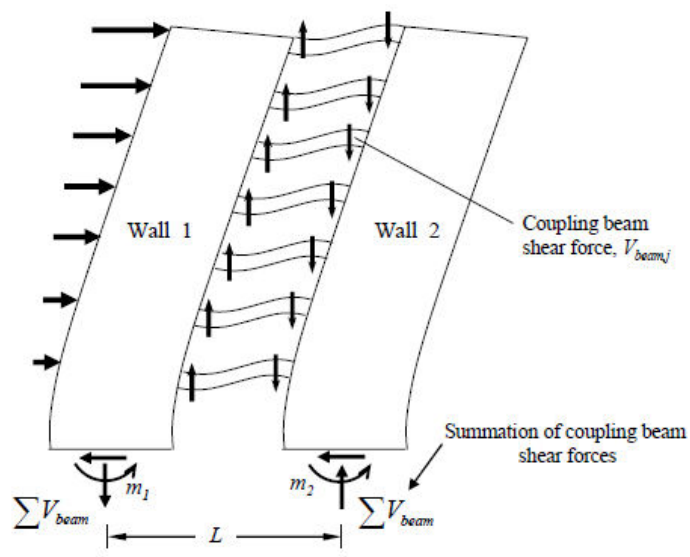

Figure 2. Deifinition of Coupling Ratio (CR)

(Draft ASCE Committee on Composite Construction v8)

$C R=\frac{L \sum \text { Vbeam }}{L \sum \text { Vbeam }+\sum \mathrm{m} i}=\frac{L \sum \text { Vbeam }}{O T M}$

Where, $\sum \mathrm{V}_{\text {beam }}$ is the accumulation of coupling beam shear acting at the adge of one wall pier, $\mathrm{L}$ is the lever arm between the centroids of the wall piers, and $m i$ is the overturning moment resisted by wall $i$.

By convention, the calculation of $\mathrm{CR}$ is made at the base of the wall when the system forms a mechanism. In this idealized case, the coupling beams are assumed to maintain their plastic shear capacity as the wall piers yeld. This definition is adopted here, in this analyze to get structure performance.

The choice of a suitable coupling ratio (CR) depends greatly on the judgment and experience of the designer. Certainly, there is a little structural benefit to providing a low $\mathrm{CR}$ as the reduction in wall moments and lateral drifts will be relatively inconsequential. An example of a low CR that is generally not considered in design is the small level of coupling offerd simply by the presence of a slab coupling the wall piers (Lim 1989). Generally the slab is assumed to provide no resistance to lateral forces, although the slab-to-wall connections must be detailed to have necessary ductility to statisfy compatibility requirements. On the other hand, it has been shown that a high CR results in ordinately large ductility demands on reinforced concrete coupling beams (Harries 2001). A high CR implies reduce moment demands on the wall piers, allowing smaller wall sections. However, the high $\mathrm{CR}$ also results in a greater axial coupled, resulting in a greater like hood that the walls will experience net tension and uplift. Similarly, the axial compression forces that result may subtantially reduce the ductility of the wall members. These combined effects indicates that a high CR may result in an impractical design scenario.

Research reported by El-Tawil et al (2002b) on 12story coupled wall systems (Figure 3a) quantifies the effects of the CR. System with high CR $(C R \geq 60 \%)$ had more widespread cracking in the upper portions of the wall piers and suffered earlier crushing failure of the wall compared to system with lower coupling ratios. At the other extreme, co coupling at all $(\mathrm{CR}=0 \%)$ can also lead to inefficient and comparatively poor behavior. For examples, of all the prototypes considered in the reasearch, the system without any coupling experienced the highest base wall rotations, story drfit, shear distortions and deflections, in addition to experiencing concrete crushing in the plastic hinge region. System with coupling ratios $30 \%$ to $45 \%$ performed best amongst the systems considered and were most economical in the sense that they required less steel and concrete materials. Applying performance based design approcah, Harrie and McNiece (2006) developed an efficient design for two 30-story reinforced concrete structure having CR value $67 \%$ and $78 \%$. In this design, five coupling beam details were distributed over the height (Figure $3 b$ ). They recommend grouping coupling beams and allowing for vertical redistribution of coupling beam forces in order to minimize demands on the wall piers while continuing to provide coupling action consistent with the expected behavior of the system. Xuan et al (2007) design an efficient reinforced concrete 15-story structure using three groups of coupling beams having the largest capacities in the lower one half of the wall height (Figure $3 \mathrm{c}$ ). The resulting CR for this structure was approximately $80 \%$. Xuan and Shahrooz (2005) also recommended grouping coupling beams based on the distribution of coupling beam shear demand over the building height. In a case where uniform wall and concrete beam details were provide, Harries et al (2004b) demonstrate the design of a ten story structure having a CR 74\%.

Although a design exhibiting good behavior and statisfying all performance criteria was obtained in each case discussed above, the designs would not be strictly compliant with current building code requirements for strength based code design. The conventionally and diagonally reinforced concrete coupling beams have a number of code presrcribe and practical constructability limitation (Harries et al. 2005), the use of steel coupling beams and thus HCWS overcome many of these. Where, the use section effectivelly elimintes limitation on beam shear capacity and thus the selection of the CR.

The forgoing discussion indicates that various researchers have successfully utilized a wide range of coupling ratios. Based on publish work, it appears that there is a little structural advatage to providing a CR less than about $30 \%$. Similarly, an upper limit to ensure sound strucutural performance is in the range $60 \%$ to $80 \%$. With HCWS, this upper limit, unlike CWS where the CR upper limit is controlled by beam shear limitations, is largely based on controlling the wall pier axial load developed as a result of the coupling action which, combined with the factored gravity load acting on the compression pier, should not overload the wall pier in compression. 


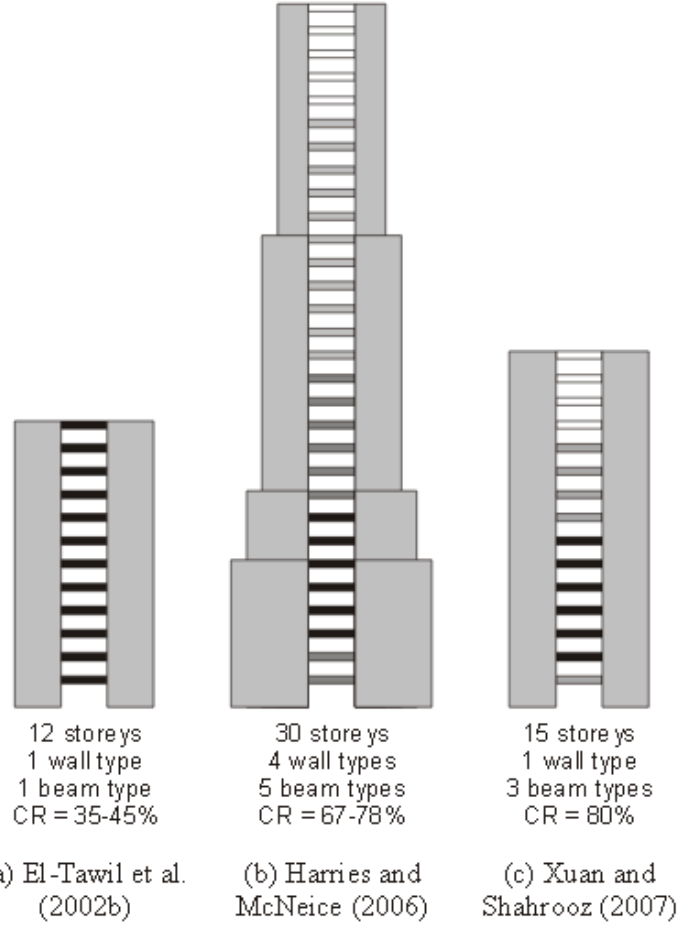

Figure 3. Schematic Representation of Wall and Beam Capacity Distribution and Resulting CR

(Draft ASCE Committee on Composite Constuction v8)

\section{B. Modelling Parameters}

In the following sections, beneficial effect of couple wall systems are sistematically studied using modelling parameters so that can get an expected result. In this study, two modelling parameter are used coupling beam materials and aspect ratio. Where, aspect ratio is length to deep ratio $(\ln / \mathrm{h})$ which is will seperated to deep coupling beams, medium coupling beams, and short coupling beams. On the other side, materials that can be used for analysis are reinforced concrete and steel.

\section{Coupling Beam Materials}

The structural response of coupled wall is complicated by the fact that the system is comprised of components that exihibit significantly different ductility demands between walls and coupling beams. The idealized lateral force-deformation response of a coupled wall structure as the sum of the individual cantilever pier flexular respons and the frame-like response of the coupling action provided by the beams. In contrast to the walls, the coupling beams must undergo significant inelastic deformations in order to allow the structure to achieve its lateral yield strength. As the system continues to deform laterlly in a ductile manner, the wall ductility ratio, defined as the ratio of the ultimate deformation to that at yield, is significantly smaller than that of the beams. If the beams are unable to cope with the high ductility demands imposed upon them, the coupling action deteriorates leading to a drop in the lateral resistance and a dramatic change in the dynamic properties as the system eventually degenerates into two (or more) independent, uncoupled wall piers. The shear force and deformation demands expected on coupling beams during a design-level seismic event, coupled with their low span-to-depth ratio, and the degradation of shear resisting mechanisms attributed to concrete under load reverseals, had led designer to provide special diagonal reinforcement which has complex and unefficient construction. Steel coupling beams is an alternative to reinforced concrete coupling beams. So, in this study, coupling beams will be analyzed with two different materials. CWS structure will be analyze using RC coupling beams and RC walls, and HCWS structure will use steel coupling beams and RC walls.

\section{Aspect Ratio}

Aspect ratio for coupling beams has an important role to determine process of energy dissipated in system and represent the degradation of shear resisting mechanism. Three aspects ratio that used for analyzed are aspect ratio $\ln / \mathrm{h} \leq 2$ (deep coupling beam), aspect ratio $2<\ln / \mathrm{h}<4$ (medium coupling beams), and aspect ratio $\mathrm{ln} / \mathrm{h} \geq 4$ (short coupling beams). Where, $\ln$ is coupling beams length that measure from beam-wall interface and $h$ is depth of coupling beams. Aspect ratio used to determine depth of $\mathrm{RC}$ coupling beams. Steel coupling beams designed by similarelastic stiffness and strength to reinforced concrete coupling beams. Coupling beams aspect ratio and dimension figure at Table 1 .

Table 1. Coupling Beam Aspect Ratio and Dimension

\begin{tabular}{|c|c|c|c|}
\hline Storey & $\begin{array}{l}\text { Aspect } \\
\text { Ratio }\end{array}$ & $\begin{array}{l}\text { Reinforced Concrete } \\
\text { Coupling Beam }\end{array}$ & $\begin{array}{c}\text { Steel } \\
\text { Coupling Beam }\end{array}$ \\
\hline 01 to 10 & $\ln / \mathrm{h} \leq 2$ & BK 1000X500 & IWF 700x300x13×24 \\
\hline 11 to 20 & $2<\ln / \mathrm{h}<4$ & BK 750X400 & IWF 600x200x11x17 \\
\hline 21 to 25 & $\ln / \mathrm{h} \geq 4$ & BK 500X300 & IWF $200 \times 200 \times 8 \times 12$ \\
\hline
\end{tabular}

\section{Element Analysis Methods}

Several types of linier and nonlinier analysis models have been used to model shear walls. Three models fall into three main classes based on Draft ASCE Committee on Composite Construction v8 are: a) equivalent frame models, b) multi-spring models, and c) continum finite element models. In the equivalent frame model, the finite width of the walls is generally represented using rigid elements, while wall behavior is modelled using an equivalent beam-column placed at the wall centroid. In these models, the cross-sectional response is represented by resultant or fiber section models. In the multi spring models, the behavior of the wall is represented using a number of series or parallel springs to stimulate the inelastic axial, shear, and bending behavior of the wall panels, while rigid elements are used to represent the physical dimension of the wall. In the continum finite element, the wall section is subdivided into a number of elements where element size is sensitivity issues. These models produce stresses, which must then be integrated to obtain the forces required for structural design. Finite element models were generally shunned because the modelling tools remain limited in their abilities and must be operated by knowledgeable and competent analysts to produce reasonable and trushworthy result. Beside that, location of the wall neutral axis chages subtantially during nonlinier analysis, beam-column element can be grossly inaccurate unless they adequately account for the effects of axial-flexural interaction. For this reason, 
fiber-section models are recomended for this study to capture the wall pier behavior.

In a fiber section model, the section is subdivided into a number of fiber (not necessarily of equal area) and the stresses are integrated over the cross-sectional area to obtain stress resultants such as forces or moments. The fiber section model generally make use of a number of assumptions: i) Plane sections remain plane in ending. It is generally accepted that this assumption is reasonably accurate even well into the inelastic range, ii) Shear and torsion stresses are neglected. For this reason the fiber section method is generally used for analysis of flexure dominated mebers, where Euler-Bernaulli beam theory can be reasonably apply, iii) Althought constitutive relations are typically defined as uniaxial, multi-axial stress states can be included by increasing the concrete strength and or by modifying the concrete pos-peak response, and iv) Concrete cracking is taken into account. However, the cracking is considered to be smeared and normal to the member axis as a result of plane section assumption.

Several types of linier and nonlinier analysis models has been used to model coupling beams. Based on ACI Structural Journal by David Naish et al., two models were considered: one using a rotational spring at the ends of the beam to account for both nonlinier flexural and shear deformation, and one using a nonlinier sheardisplacement spring at beam midspan to account for both flexural and shear deformations. In addition, both of the models incorporate elastic slip/extension springs to account for softening due to slip/extension deformations at the beam-wall interface. Simple nonlinier models, either moment-hinge or shear-hinge, accurately represent the load-deformation behavior of test beams. The flexural hinge model better matches the test results in the unloading and reloading range.

The coupling beams should be modeled using elements that account for both flexural and shear properties of the beam. In this study, coupling beams analyzed using moment-hinge rotation model. This model using a rotational spring at the ends of the beam to account for both nonlinier flexural and shear deformation, and represented coupling beam plastification based on determined rotation deformation limits.

\section{PBDM (Performance Based Design Method)}

Performance based design method allows the designer to select how the structure will behave and provides the framework for selecting performance objectives for the structure. Performance objectives are typically displacement-based or force-based objectives, however, they can address any aspect of building performance. For instance, for reinforced concrete coupled walls, a key performance objective is to have a beam that is reasonably constructible (Harries et al 2004, Harries and McNiece 2006, and Xuan et al. 2007).

Three basic components to analyze structure coupled wall system with PBDM: i) Definition of a performance objective, categorized in the guidlines by three primary performance levels: Immediate Occupancy (IO), Life Safety (LS), and Collapse Prevention (CP); ii) Demand prediction using four alternative analysis procedures; and iii) Acceptance criteria using force and/or deformation limits which are intended to statisfy the desire performance objective.

\section{Performance Objective}

Performcance objective have planned in PBDM will be achieve if fulfilled the engineer and owner demands. Engineer demands will be fulfilled if they can count earthquake forces and performance of the structure, and that thing can be understand by owner. Performance objective structure denoted by situation and condition of level damage from physical structure, and service ability structure.

In the most building code apllications, the desired performance of a structure is that it will statisfy Life Safety (LS) requierments at the design level earthquake (conventionally defined as having a $10 \%$ probability of exccedance in 50 years (10/50)) and Collapse Prevention $(\mathrm{CP})$ requirements at the maximum credible event $(2 \%$ in 50years (2/50)). A third performance objective, Immediate Occupancy (IO), associated with a frequent but mild event, in example an earthquake with a probability of exceedance of $50 \%$ in 50 years $(50 / 50$ earthquake). These three performance objectives (Figure4) are therefore recomended for both structure CWS and HCWS.

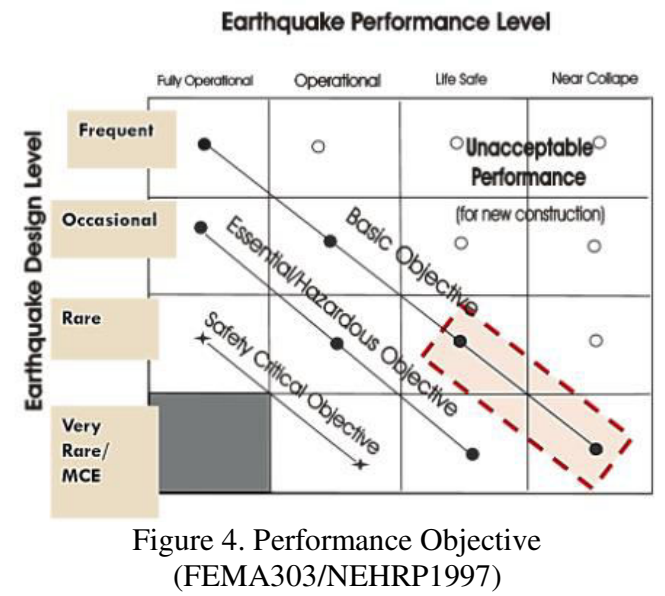

2. Structure Analysis Method

The analysis procedures recomended in ASCE/SEI41-13 are Linear Static-LSP (Equivalent Lateral ForceAnalysis, ELFA), Linier Dynamic-LDP (Modal Respons Spectrum Analysis, MRSA), Nonlinier Static-NSP (Pushover), Nonlinier Dynamic-NDP (Nonlinier Time History Analysis, NLTHA). The choice of analytical method is subject to limitations based on building characteristics. The linier procedures assume linier component and system behavior, but incorporate adjusments to global response parameters to account for the possibility of nonlinier system behavior during the design seismic event. The current recomendation procedures can be used for hybrid couple wall system analysis. But, prefer using nonlinier procedures than linier procedures.

Of the two nonlinier procedure permitted. The nonlinier static procedure, also known as a pushover analysis, employs simplified nonlinier techniques to quantify seismic behavior. Pushover have become popular because they avoid the complexity of a nonlinier response history analysis yet incorporate significant 
aspects of system degradation that are critical to seismic behavior. However, the pushover method does not directly account for the presence of higher modes, particulary critical in taller buildings, and is therefore limited to low to mid-rise buildings whose behavior is dominated by first mode response. However, preference is given to NDP-Nonliner Dynamic Procedure (NLTHA) over pushover analysis to get a better actual behavior from structure system. In this procedure, a conventional response spectrum analysis, like equivalent lateral force analysis and modal response spectrum analysis, is used to derive detailing from elements that composed structure.

Equivalent lateral force analysis is a procedure that represented lateral static force as a storey forces in every level. Spectral at fundamental period determine story forces and distributed over the height of the entire structure. In these procedure, structure behavior is dominated by first mode response, so that been used in analysis just spectral acceleration related to first mode. Seismic base shear, V, in each direction must be stipulated by Equation(1).

$$
\begin{aligned}
& \mathrm{V}=\mathrm{C}_{\mathrm{s}} \mathrm{W} \\
& \mathrm{C}_{\mathrm{s}}=\mathrm{S}_{\mathrm{DS}} /(\mathrm{R} / \mathrm{I}) \\
& \mathrm{C}_{\mathrm{s}}=\mathrm{S}_{\mathrm{DS}} / \mathrm{T}(\mathrm{R} / \mathrm{I}) \\
& \mathrm{C}_{\mathrm{s}}=0.044 \mathrm{~S}_{\mathrm{DS}} \mathrm{I} \geq 0.01 \\
& \mathrm{~T}=\mathrm{C}_{\mathrm{t}} \mathrm{h}_{\mathrm{n}}{ }^{\mathrm{x}}
\end{aligned}
$$

Where, Cs is respons seismic coefficient, which Cs value less than $\mathrm{Eq}(3)$ and greater than $\mathrm{Eq}(4)$. W is seismic effective weight and $S_{D S}$ is respons spectrum accelaration in range short period. $\mathrm{R}$ is response modiffication factor, $\mathrm{I}$ is importance factor, and $\mathrm{T}$ is fundamental period of the structure.

Modal response spectrum analysis basically is dynamic procedure which load and damping in each storey level represents structure dynamic characteristic. Analysis should be done to determine natural mode of the structure. Amount of modal that included in analysis must be enough to get 90 percent modal mass combined from actual mass in every orthogonal horizontal direction (Table 2).

The presences of higher modes significantly influence base shear calculation in higher building structure. Higher mode effect higher lateral force distribution at the top of structure. Two linier analysis procedur produce base shear at Table 3, which that base shear used to get design parameters for modal spectrum analysis. Structure behavior respons can be calculated using respectively modal properties and response spectrum divided with value $(\mathrm{R} / \mathrm{I})$, and for deformation and interstory drift multiplied with with value $\left(\mathrm{C}_{\mathrm{d}} / \mathrm{I}\right)$.

Response spectrum loading will be different for every single structure, depends on scale factor. Scale factor obtained based on base shear, importance factor, and response modiffication factor (Eq. (6) and (7))

$$
\mathrm{FS} 1=\max [(0.85 \mathrm{~V} / \mathrm{Vt}), 1]
$$$$
\mathrm{FS} 2=(\mathrm{FS} 1 . \mathrm{g}) /(\mathrm{R} / \mathrm{I})
$$

Where, $\mathrm{V}$ is ELFA base shear, Vt is base shear from required modal combination, and $g$ is gravity

\begin{tabular}{|c|c|c|c|c|c|c|c|c|}
\hline \multirow[b]{2}{*}{ Mode } & \multicolumn{4}{|c|}{ CWS } & \multicolumn{4}{|c|}{ HCWS } \\
\hline & $\begin{array}{c}\text { Period } \\
{[\mathrm{sec}]}\end{array}$ & $\mathbf{U X}$ & UY & RZ & $\begin{array}{c}\text { Period } \\
{[\mathrm{sec}]}\end{array}$ & $\mathbf{U X}$ & UY & $\mathbf{R Z}$ \\
\hline 1 & 2.764 & 0 & 64.92 & 0 & 3.033 & 69.38 & 0 & 0 \\
\hline 2 & 2.704 & 65.5 & 64.92 & 0 & 2.884 & 69.38 & 66 & 0 \\
\hline 3 & 1.593 & 65.5 & 64.92 & 76.09 & 2.254 & 69.38 & 66 & 76.6 \\
\hline 4 & 0.716 & 83.48 & 64.92 & 76.09 & 0.891 & 85.42 & 66 & 76.6 \\
\hline 5 & 0.676 & 83.48 & 82.98 & 76.09 & 0.775 & 85.42 & 66 & 87.7 \\
\hline 6 & 0.585 & 83.48 & 82.98 & 87.84 & 0.68 & 85.42 & 83.75 & 87.7 \\
\hline 7 & 0.355 & 83.48 & 82.98 & 91.95 & 0.465 & 90.85 & 83.75 & 87.7 \\
\hline 8 & 0.349 & 89.89 & 82.98 & 91.95 & 0.438 & 90.85 & 83.75 & 92.4 \\
\hline 9 & 0.293 & 89.89 & 89.93 & 91.95 & 0.293 & 93.81 & 83.75 & 92.4 \\
\hline 10 & 0.244 & 89.89 & 89.93 & 94.21 & 0.293 & 93.81 & 90.43 & 92.4 \\
\hline 11 & 0.219 & 93.17 & 89.93 & 94.21 & 0.287 & 93.81 & 90.43 & 94.9 \\
\hline 12 & 0.186 & 93.17 & 89.93 & 95.69 & 0.21 & 93.81 & 90.43 & 96.4 \\
\hline 13 & 0.174 & 93.17 & 93.44 & 95.69 & 0.206 & 95.61 & 90.43 & 96.4 \\
\hline 14 & 0.158 & 95.16 & 93.44 & 95.69 & 0.174 & 95.61 & 93.8 & 96.4 \\
\hline 15 & 0.151 & 95.16 & 93.44 & 96.48 & 0.166 & 95.61 & 93.8 & 97.3 \\
\hline 16 & 0.127 & 95.16 & 93.44 & 97.1 & 0.155 & 96.72 & 93.8 & 97.3 \\
\hline 17 & 0.123 & 96.21 & 93.44 & 97.1 & 0.138 & 96.72 & 93.8 & 98 \\
\hline 18 & 0.122 & 96.21 & 95.43 & 97.1 & 0.123 & 97.53 & 93.8 & 98 \\
\hline 19 & 0.11 & 96.21 & 95.43 & 97.6 & 0.121 & 97.53 & 95.71 & 98 \\
\hline 20 & 0.1 & 97.02 & 95.43 & 97.6 & 0.119 & 97.53 & 95.71 & 98.4 \\
\hline
\end{tabular}

acceleration. Importance factor, I, for office building is 1 and response modiffication factor , $\mathrm{R}$, for single system special reinforced concrete shear wall is 6 . Scale factor for response spectrum load can be seen in Table 4 .

Table 2. Modal Mass Partisipation

Table 3. Base Shear from Linier Analysis Procedures

\begin{tabular}{cccc}
\hline \multirow{2}{*}{ Structure } & \multirow{2}{*}{ Item } & \multicolumn{2}{c}{ Base Shear[kN] } \\
\cline { 3 - 4 } & & ELFA & MRSA \\
\hline \multirow{2}{*}{ CWS } & FX & 2378 & 2950.328 \\
& FY & 2378 & 2989.4069 \\
\hline \multirow{2}{*}{ HCWS } & FX & 2352 & 2391.3234 \\
& FY & 2352 & 2822.3343 \\
\hline
\end{tabular}

Table 4. Response Spectrum Scale Factor

\begin{tabular}{cccccc}
\hline Structure & Dir & V & Vt & FS1 & FS2 \\
\hline \multirow{2}{*}{ CWS } & UX & 2378 & 2950.328 & 1 & 1.634 \\
& UY & 2378 & 2989.407 & 1 & 1.634 \\
\hline \multirow{2}{*}{ HCWS } & UX & 2352 & 2391.323 & 1 & 1.634 \\
& UY & 2352 & 2822.334 & 1 & 1.634 \\
\hline
\end{tabular}

Both linier procedure, static and dynamic has been used to design elemets of the structure system. Beam elements design based on Section 21.5 SNI2847:2013, which applies to structure components with special moment resisting frame to resist lateral forces. On the other side, column elements design based on Section21.6 SNI2847:2013, which applied to structure components who resist bending and axial forces especially axial compression forces from load combination. Section 21.9 SNI2847:2013 applied to special reinforced concrete shear wall and the entire components wall included coupling beams and wall pier.

In these study, structure composed from their elements: three types of beam; primary beams: external beam and interior beam, and secondary beam (Table 5), five types of column (Table 6), and three types for both shear wall (Table 7) and coupling beams (Table 8 and Table 9). 
Table 5. Beam Reinforcement

\begin{tabular}{ccccc}
\hline \multirow{2}{*}{ Type } & \multirow{2}{*}{ Loc. } & \multicolumn{2}{c}{ Longitudinal Reinf. } & Transversal \\
\cline { 3 - 4 } & Left (i) & Right (j) & Reinf. \\
\hline PB Ex & Top & 5 D-22 & 5 D-22 & D10@ 100 \\
B 400X700 & Bottom & 3 D-22 & 3 D-22 & \\
PB In & Top & 8 D-22 & 8 D-22 & D10@ 100 \\
B 400X700 & Bottom & 3 D-22 & 3 D-22 & \\
SB & Top & 2 D-22 & 2 D-22 & D10@ 125 \\
B 300X500 & Bottom & 4 D-22 & 4 D-22 & \\
\hline
\end{tabular}

Table 6. Column Reinforcement

\begin{tabular}{cccc}
\hline Story & $\begin{array}{c}\text { Dimension } \\
\text { [mm] }\end{array}$ & $\begin{array}{c}\text { Longitudinal } \\
\text { Reinforcement }\end{array}$ & $\begin{array}{c}\text { Transversal } \\
\text { Reinforcement }\end{array}$ \\
\hline 01 to 05 & K1 - 900X900 & 22 D-22 & 2D-10 @ 100 \\
06 to 10 & K2 - 800X800 & 20 D-22 & 2D-10 @ 100 \\
11 to 15 & K3 - 700X700 & 18 D-19 & 2D-10 @ 100 \\
16 to 20 & K4 - 600X600 & 14 D-19 & 2D-10 @ 100 \\
21 to 25 & K5 - 500X500 & 14 D-19 & 2D-10 @ 100 \\
\hline
\end{tabular}

Table 7. Shear Wall Reinforcement

\begin{tabular}{cccc}
\hline Storey & Type & $\begin{array}{c}\text { Thick } \\
{[\mathbf{m m}]}\end{array}$ & $\begin{array}{c}\text { Longitudinal Reinf. } \\
\text { and Space[mm] }\end{array}$ \\
\hline \multirow{2}{*}{ 01 to 10 } & W50 & 500 & D22-150 \\
& W30 & 300 & D22-300 \\
\multirow{4}{*}{ 11 to 20 } & W50 & 500 & D22-150 \\
& W25 & 250 & D22-300 \\
\multirow{2}{*}{ 21 to 25 5 W50 } & 500 & D22-150 \\
& W20 & 200 & D22-300 \\
\hline
\end{tabular}

Table 8. RC Coupling Beam Reinforcement

\begin{tabular}{cccccc}
\hline \multirow{2}{*}{ Type } & Loc. & \multicolumn{2}{c}{ Longitudinal Reinf. } & Transversal & Diagonal \\
Left (i) & Right (j) & Reinf. & Reinf. \\
\hline \multirow{2}{*}{ CB 1000 } & Top & 4 D25 & 4 D25 & 6 D16@130 & 16 D22 \\
& Bottom & 4 D25 & 4 D25 & & \\
CB 750 & Top & 3 D22 & 3 D22 & 4 D16@100 & 16 D19 \\
& Bottom & 3 D22 & 3 D22 & & \\
CB 500 & Top & 3 D19 & 3 D19 & D16@100 & - \\
& Bottom & 3 D19 & 3 D19 & & \\
\hline
\end{tabular}

Table 9. Steel Coupling Beam Reinforcement

\begin{tabular}{|c|c|c|c|c|}
\hline \multirow{2}{*}{$\begin{array}{c}\text { Coupling Beam } \\
\text { Profil } \\
\end{array}$} & \multirow{2}{*}{$\begin{array}{c}\text { Le } \\
{[\mathrm{mm}]}\end{array}$} & \multicolumn{2}{|c|}{ Vertical Transfer Reinf. } & \multirow{2}{*}{$\begin{array}{l}\text { Edge } \\
\text { Plate } \\
\end{array}$} \\
\hline & & First & Second & \\
\hline IWF $700 \times 300 \times 13 \times 24$ & 600 & $4 \mathrm{D} 25$ & 2D25 & $10 \mathrm{~mm}$ \\
\hline IWF 600x200x11x17 & 350 & $4 \mathrm{D} 22$ & 2D22 & $10 \mathrm{~mm}$ \\
\hline IWF 200x200x8x12 & 200 & $4 \mathrm{D} 22$ & 2D22 & $10 \mathrm{~mm}$ \\
\hline
\end{tabular}

Nonlinier time history procedure is the most popular method that can be used to determine structure behavior reponse. In these procedure, the result is more accurate than others procedures. NLTHA must be consist of mathematic models that calculated histeristic behavior from nonlinier elements and determine structure response with numerical integration to time history of ground motion acceleration and compatible with response spectrum design for reviwed site. The permited models, two dimensional model and three dimensional model, were used as the basis for analysis, elements and components of the building shall be analyzed for forces and deformations assosiated with the application of the suite of ground motion. In this study, three dimensional model was used as the basis for elements and components of the structure analysis, and the required suite of ground motions must be selected based on how the result will be analyzed (Table 10).

Table 10. Summary of Required Number of Ground Motion Acceleration History Records and Analysis Cases for NDP (ASCE/SEI41-13)

\begin{tabular}{ccc}
\hline Condition & $\begin{array}{c}\text { Method of } \\
\text { Computing Result }\end{array}$ & $\begin{array}{c}\text { Basic Performance Objective Equivalent } \\
\text { to New Building Standards }(\text { BPON })\end{array}$ \\
\hline $\begin{array}{c}\text { Far Field } \\
(>\mathbf{5 m} / \mathbf{3 m i})\end{array}$ & $\begin{array}{c}\text { Rata-rata } \\
\text { Maksimum }\end{array}$ & $\begin{array}{c}\text { Record pairs } \geq 10, \text { no rotation } \\
\text { a }\end{array}$ \\
Near Field & Rata-rata & Record pairs $\leq 9$, no rotation ${ }^{\mathrm{a}}$ \\
$(<\mathbf{5 k m} / \mathbf{3 m i})$ & Maksimum & Record pairs $\geq 7$, with rotation ${ }^{\circ}$ \\
${ }^{\text {a }}$ Record pairs are applied in a random orientation \\
${ }^{\circ}$ Record pairs are applied to the model with the fault-normal component aligned with \\
respect to the orientation of the governing fault and the principal axes of the building
\end{tabular}

\section{Acceptance Criteria}

ASCE/SEI41-13 provides table for acceptance criteria for common strucutral system and their elemets. The value in ASCE/SEI41-13 are for existing structures and may underestimate the capacity of well-detailed new construction. These values are therefore considered conservative and are recommend for performance-based design of hybrid coupled wall systems until more appropriate acceptance criteria become available.

Steel coupling beam response is expected to be similar to shear link response in eccentrically braced frames $(\mathrm{EBF})$. The acceptance criteria for shear link in Table 11 (ASCE/SEI41-13 Table 9-6), based upon plastic rotation angle. In applying the EBF criteria to hybrid coupling beams, it is important that the effective length of the beam (g) is used (Eq. (8)). However, RC coupling beams, categorized as RC3 (weaker spandrel or coupling beam), have acceptance criteria in Table 12 (ASCE/SEI41-13 Table 10-19) based on plastic rotation angle. To be consistent with recomendations in this paper, nominal coupling beam strengths should be subtituted for expected strength by $1.1 \mathrm{R}_{\mathrm{y}}$.

Table 11. Acceptance Criteria For NDP-Steel CB

\begin{tabular}{cccc}
\hline \multirow{2}{*}{ EBF Link Beam j,k } & \multicolumn{3}{c}{ Acceptance Citeria } \\
\cline { 2 - 3 } & \multicolumn{3}{c}{ Plastic Rotation Angle [rad] } \\
\hline$e \leq \frac{1.6 M_{C E}}{V_{C E}}$ & 0.05 & LS & CP \\
$e \geq \frac{2.6 M_{C E}}{V_{C E}}$ & & \multicolumn{2}{c}{ same as for beam } \\
$\frac{1.6 M_{C E}}{V_{C E}}<e<\frac{2.6 M_{C E}}{V_{C E}}$ & & \multicolumn{2}{c}{ Linier Interpolation }
\end{tabular}

$\mathrm{j}$ Deformation is the rotation angle between link and beam outside link or column $\mathrm{k}$ Value are for link beams with three or more web stiffeners,

if no stiffeners, divided value by 2 . 
Table 12. Acceptance Criteria For NDP-RC CB

\begin{tabular}{lccccc}
\hline \multirow{2}{*}{$\begin{array}{l}\text { Coupling Beam } \\
\text { Reinforcement }\end{array}$} & $V$ & \multicolumn{4}{c}{ Acceptance Citeria } \\
\cline { 2 - 5 } \cline { 5 - 6 } & $t_{w} l_{w} \sqrt{f_{c}^{\prime}}$ & & Plastic Rotation Angle [rad] \\
\hline $\begin{array}{l}\text { Conventional longitudinal } \\
\text { reinforcement with }\end{array}$ & $\leq 3$ & & LS & CP \\
$\begin{array}{l}\text { conforming transverse } \\
\text { reinforcement }\end{array}$ & $\geq 6$ & 0.02 & 0.025 & 0.05 \\
$\begin{array}{l}\text { Conventional longitudinal } \\
\text { reinforcement with }\end{array}$ & $\leq 3$ & 0.006 & 0.02 & 0.035 \\
$\begin{array}{l}\text { nonconforming } \\
\text { transverse reinforcement } \\
\text { Diagonal reinforcement }\end{array}$ & $\geq 6$ & 0.005 & 0.01 & 0.025 \\
\hline
\end{tabular}

$\mathrm{g}=\mathrm{g}_{\text {clear }}+0.6 \mathrm{~L}_{\mathrm{e}}$

$\mathrm{V}_{\mathrm{u}}=4.05 \cdot \sqrt{ } \mathrm{f}^{\mathrm{f}} \mathrm{c} \cdot\left(\mathrm{b}_{\mathrm{w}} / \mathrm{b}_{\mathrm{f}}\right)^{0.66} \cdot \beta_{1} \cdot \mathrm{b}_{\mathrm{f}} \cdot \mathrm{L}_{\mathrm{e}}$.

$\left[\left(0.58-0.22 \beta_{1}\right) /\left(0.88+\mathrm{g}_{\text {clear }} / 2 \mathrm{~L}_{\mathrm{e}}\right)\right]$

$\mathrm{V}_{\mathrm{u}}=1.1 \mathrm{R}_{\mathrm{y}} \cdot \mathrm{V}_{\mathrm{n}}$

$\mathrm{V}_{\mathrm{n}}=2 \mathrm{R}_{\mathrm{y}} \cdot \mathrm{M}_{\mathrm{p}} / \mathrm{g}_{\text {clear }}$

Reinforced concrete wall response shall be considered to be dominated by flexural action. As such, their performance should be judge based on acceptance criteria in Table 13 (ASCE/SEI41-13 Table 10-19). The permited plastic hinge rotation is a function of the axial load acting on the piers. Beside that, beam elements and column elements should be judge based on Table 14 and Table 15 (ASCE/SEI41-13 Table 10-7 \& Table 10-8).

Table 13. Acceptance Criteria For NDP-Shear Walls

\begin{tabular}{|c|c|c|c|c|c|}
\hline \multirow{3}{*}{$\frac{\left(A_{s}-A_{s}^{\prime}\right) f_{y}+P}{t_{w} l_{w} f_{c}^{\prime}}$} & \multirow{3}{*}{$\frac{V}{t_{w} l_{w} \sqrt{f_{c}^{\prime}}}$} & \multirow{3}{*}{$\begin{array}{l}\text { Conf. } \\
\text { Bound. }\end{array}$} & \multicolumn{3}{|c|}{ Acceptance Citeria } \\
\hline & & & \multicolumn{3}{|c|}{ Plastic Rotation Angle [rad] } \\
\hline & & & IO & LS & CP \\
\hline$\leq 0.1$ & $\leq 3$ & Yes & 0.005 & 0.015 & 0.02 \\
\hline$\leq 0.1$ & $\geq 6$ & Yes & 0.004 & 0.01 & 0.015 \\
\hline$\geq 0.25$ & $\leq 3$ & Yes & 0.003 & 0.009 & 0.012 \\
\hline$\geq 0.25$ & $\geq 6$ & Yes & 0.0025 & 0.005 & 0.01 \\
\hline$\leq 0.1$ & $\leq 3$ & No & 0.002 & 0.008 & 0.015 \\
\hline$\leq 0.1$ & $\geq 6$ & No & 0.002 & 0.006 & 0.01 \\
\hline$\geq 0.25$ & $\leq 3$ & No & 0.001 & 0.003 & 0.005 \\
\hline$\geq 0.25$ & $\geq 6$ & No & 0.001 & 0.002 & 0.004 \\
\hline
\end{tabular}

Table 14. Acceptance Criteria For NDP-Beam Elements

\begin{tabular}{|c|c|c|c|c|c|}
\hline \multirow{3}{*}{$\frac{\rho-\rho^{\prime}}{\rho_{\text {bal }}}$} & \multirow{3}{*}{$\frac{V}{b_{w} d \sqrt{f_{c}^{\prime}}}$} & \multirow{3}{*}{$\begin{array}{l}\text { Trans. } \\
\text { Reinf. }\end{array}$} & \multicolumn{3}{|c|}{ Acceptance Citeria } \\
\hline & & & \multicolumn{3}{|c|}{ Plastic Rotation Angle [rad] } \\
\hline & & & IO & LS & CP \\
\hline$\leq 0.0$ & $\leq 3(0.25)$ & $\mathrm{C}$ & 0.01 & 0.025 & 0.05 \\
\hline$\leq 0.0$ & $\geq 6(0.5)$ & $\mathrm{C}$ & 0.005 & 0.02 & 0.04 \\
\hline$\geq 0.5$ & $\leq 3(0.25)$ & $\mathrm{C}$ & 0.005 & 0.02 & 0.03 \\
\hline$\geq 0.5$ & $\geq 6(0.5)$ & $\mathrm{C}$ & 0.005 & 0.015 & 0.02 \\
\hline$\leq 0.0$ & $\leq 3(0.25)$ & $\mathrm{NC}$ & 0.005 & 0.02 & 0.03 \\
\hline$\leq 0.0$ & $\geq 6(0.5)$ & $\mathrm{NC}$ & 0.0015 & 0.01 & 0.015 \\
\hline$\geq 0.5$ & $\leq 3(0.25)$ & $\mathrm{NC}$ & 0.005 & 0.01 & 0.015 \\
\hline$\geq 0.5$ & $\geq 6(0.5)$ & $\mathrm{NC}$ & 0.0015 & 0.005 & 0.01 \\
\hline
\end{tabular}

Note: $\mathrm{f} c$ in $\mathrm{lb} / \mathrm{in}^{2}(\mathrm{MPa})$

$\mathrm{C}$ and $\mathrm{NC}$ are Conforming and Nonconforming for transversal reinforcement
Table 15. Acceptance Criteria For NDP-Column Elements

\begin{tabular}{|c|c|c|c|c|c|}
\hline \multirow{3}{*}{$\frac{P}{A_{g} f_{c}^{\prime}}$} & \multirow{3}{*}{$\frac{V}{b_{w} d \sqrt{f_{c}^{\prime}}}$} & \multirow{3}{*}{$\rho=\frac{A_{v}}{b_{w} s}$} & \multicolumn{3}{|c|}{ Acceptance Citeria } \\
\hline & & & \multicolumn{3}{|c|}{ Plastic Rotation Angle [rad] } \\
\hline & & & IO & LS & CP \\
\hline$\leq 0.1$ & $\leq 3(0.25)$ & $\geq 0.006$ & 0.005 & 0.045 & 0.06 \\
\hline$\leq 0.1$ & $\geq 6(0.5)$ & $\geq 0.006$ & 0.005 & 0.045 & 0.06 \\
\hline$\geq 0.6$ & $\leq 3(0.25)$ & $\geq 0.006$ & 0.003 & 0.009 & 0.01 \\
\hline$\geq 0.6$ & $\geq 6(0.5)$ & $\geq 0.006$ & 0.003 & 0.007 & 0.008 \\
\hline$\leq 0.1$ & $\leq 3(0.25)$ & $\geq 0.0005$ & 0.005 & 0.01 & 0.012 \\
\hline$\leq 0.1$ & $\geq 6(0.5)$ & $\geq 0.0005$ & 0.004 & 0.005 & 0.006 \\
\hline$\geq 0.6$ & $\leq 3(0.25)$ & $\geq 0.0005$ & 0.002 & 0.003 & 0.004 \\
\hline$\geq 0.6$ & $\geq 6(0.5)$ & $\geq 0.0005$ & 0 & 0 & 0 \\
\hline
\end{tabular}

\section{CASE STUDY}

The analysis procedure is applied to a building in Jakarta, Indonesia. The building is in Seismic Design Category D and is situated on Site Class D soils. Coupled wall building structure designed with a special reinforced concrete shear wall system. Structure consist of 25 storey with $3.5 \mathrm{~m}$ height for each story and total height structure is $87.5 \mathrm{~m}$. Both wide and long of the structure are $24 \mathrm{~m}$. Modelling parameters has been discussed in previous section and used in analysis procedure to get behavior respons of the structure. Two mathematic models will be analyzed with PBDM, one model is RC structure with coupled wall system which connected with RC coupling beam and the other is RC structure with hybrid coupled wall system, where walls connected with steel coupling beam. Both mathematic models, CWS and HCWS, will be loaded with same vertical and lateral load, which vertical load is gravity load and lateral load is accelaration ground motions and suite to buildings site. In this study, CSI PERFORM3D was used and input parameter obtained and support by XTRACT.

\section{A. Elements Strength and Stiffnes}

Elements strength and stiffnes determined by section capacity of component structure which is from dimension and material are in inelastic behavior. Behavior of the two material are used, concrete and steel material, represented by stress-strain curve that illustrate capacity and failure of the materials. In this study, concrete material using Mander's Model, where stressstrain model is developed for concrete subjected to uniaxial compressive loading and confined by transverse reinforcement. The models allows for cyclic loading and includes the effect of strain rate. An enegy balance approach is used to predict the longitudinal compressive strain in concrete corresponding to first fracture of the transverse reinforcement by equating the strain energy capacity of the transverse reinforcement to strain energy stored in the concrete as a result of confinement. Mander's model consist of unconfined concrete (Figure5) and confined concrete (Figure 6) which analyzed based on characteristic concrete material such as compressive strength, tension strength, yield strain, failure strain, and Young's modulus. On the other side, steel material using bilinier with parabolic strain 
harderning model (Figure 7) with perfect linier elastic assumption and subjected to tension loading and yielding until reach yield strain and keep stretching until maximum tension strength and total strain with parabolic curve.

The section capacity determined by material and dimension of the component structure. Material models has been discused and the elements dimension designed based on SNI2847:2013, are used to obtained strength of the elements structure. Section capacity represent parameters characteristic of the elements based on F-D relationship (Figure 8) and shown in Table 16.

Table 16. Characteristic Parameters for Coupling Beams

\begin{tabular}{ccccccccccccc}
\hline & \multicolumn{4}{c}{ Basic F-D Relationship } & \multicolumn{3}{c}{ Strength Loss } & \multicolumn{3}{c}{ Deformation Capacities } \\
\cline { 2 - 11 } Coupling Beam Type & \multicolumn{1}{c}{ Action [kN.m] } & \multicolumn{1}{c}{ Deformation [rad] } & \multicolumn{1}{c}{ Deformation [rad] } & 1 & 2 & $\mathbf{3}$ & $\mathbf{4}$ \\
\cline { 2 - 11 } & Fy & Fu & Du & Dx & DL & DR & FR/FU & Yield & IO & LS & CP \\
\hline CB 500X1000 & 1472 & 2415 & 0.032 & 0.052 & 0.032 & 0.032 & 0.8 & 0.031 & 0.006 & 0.030 & 0.050 \\
CB 400X750 & 799.8 & 1283 & 0.032 & 0.052 & 0.032 & 0.033 & 0.8 & 0.025 & 0.006 & 0.030 & 0.050 \\
CB 300X500 & 133.2 & 192.2 & 0.032 & 0.052 & 0.032 & 0.033 & 0.8 & 0.016 & 0.005 & 0.020 & 0.040 \\
IWF 700X300X13X24 & 2272 & 3804 & 0.152 & 0.172 & 0.154 & 0.157 & 0.8 & 0.033 & 0.008 & 0.099 & 0.132 \\
IWF 600X200X11X17 & 1009 & 1732 & 0.152 & 0.172 & 0.154 & 0.157 & 0.8 & 0.028 & 0.007 & 0.085 & 0.113 \\
IWF 200X200X8X12 & 189.4 & 313.8 & 0.152 & 0.172 & 0.154 & 0.157 & 0.8 & 0.010 & 0.002 & 0.029 & 0.039 \\
\hline
\end{tabular}

Figure 8. F-D Relationship for Coupling Beam in

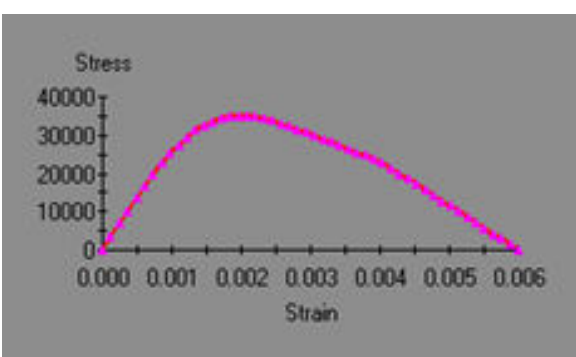

Figure 5. Stess-Strain Model for Unconfined Concrete [KPa]

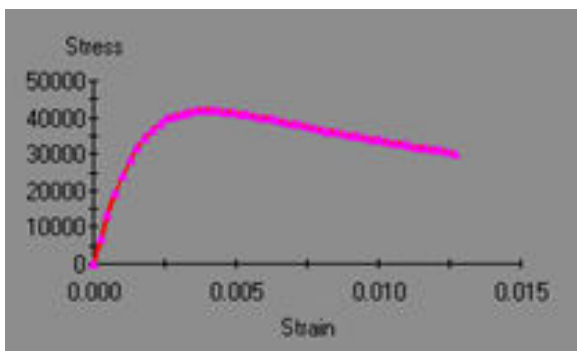

Figure 6. Stress-Strain Model for Confined Concrete [KPa]

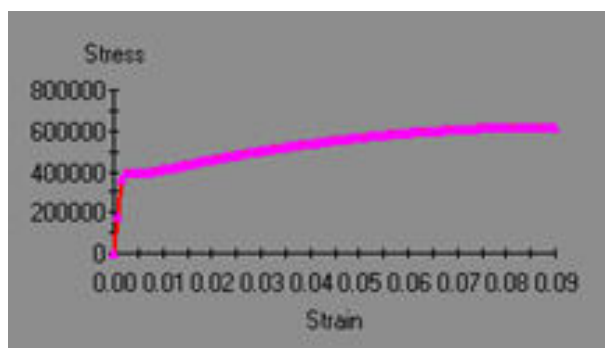

Figure 7. Stress-Strain Model for Bilinier Steel with Parabolic Strain Harderning [KPa]

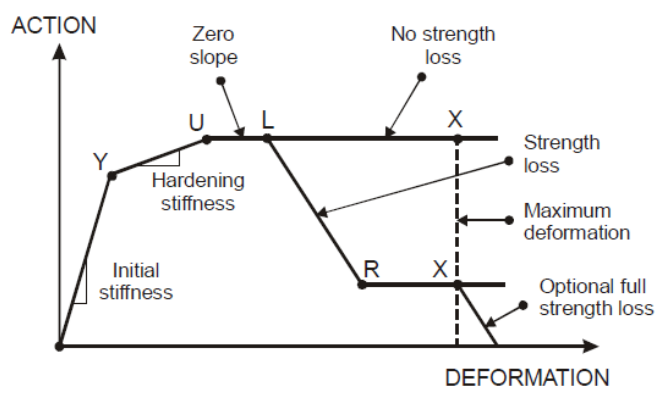

PERFORM 3D

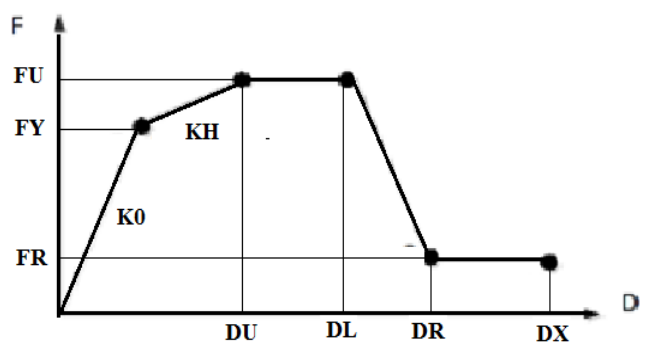

Figure 8. F-D Relationship for Coupling Beam in PERFORM 3D (advanced)

\section{B. Ground Motion}

Ground motions are use as seismic loading in nonlinier time history analysis. The mathematic models of the building shall be analyzed for forces and deformations assosiated with the application of the suite of ground motion and that is must have a propper selected and scaling process. Both record selection and scaling are equally importance processes for success of any nonlinier time history analysis-NLTHA. Before scaling ground motions, one needs to define the hazard conditions associated with a given site either through deterministic or probabilistic site-spesific hazard analysis or alternatively from USGS seismic hazard maps. The parameters that need to be considered in identifying the scenario conditions are those that have the most influence on ground motion spectral shape (Graizer and Kalkan 2009): magnitude range of anticipated significant events, distance range of the site from causative faults, site condition (site-geology generally describe shearwave velocity within $30 \mathrm{~m}$ ), basin effect (if basin exists), and directivity effect. Spectral shape defines ground motion demand characteristic on three-dimensional structure system. Therefore in selecting candidate records for NLTHA, one needs to carefully identify records whose spectral shapes are close to each other. The dependence of ground motion spectral shape on the first three parameters coloring seismic hazard condition is explained in detail. 
In general, event with larger magnitude yield wider response spectra. In order to find the degree of magnitude influence on response spectral shape, average spectral shapes of eartquakes ranging from magnitude 4.9 to 7.9 (Graizer and Kalkan. 2009). A reported in previous studies (e.g. Abrahamson and Silva. 1997), predominant period shift to higher values with increase in distance from the fault for a given earthquake. For this particular event, predominant period shifts from about $0.35 \mathrm{sec}$ at the closest distances $(0-20 \mathrm{~km})$ to $1.2 \mathrm{sec}$ at farthest fault distances (120-140km). Similar observations are valid for the other major events investigated. In addition to magnitude and distance depended, spectral shape also depend on site condition. Predominant period of spectral shape from a rock site is generally lower than of a soil site. The average spectral shape is generally describe shear-wave velocity within $30 \mathrm{~m}, \mathrm{Vs}_{30}$. In order to analyzed structure with NLTHA and based on the required suite of ground motions, a total ten far-fault strong earthquake ground motions were compiled from PEER ground motion database. These motion were recorded during seismic events with moment magnitude, $\mathrm{M}>6.5$ at far-fault distances, $\mathrm{R}_{\mathrm{jb}}$ and $\mathrm{R}_{\text {rup }}>20 \mathrm{~km}$ and belonging to ASCE 7 site classification $\mathrm{D}$. The selected ground motion records and their characteristic parameters are lsited in Table 17.

Table 17. Ground Motion Records and Their Characteristic Parameters

\begin{tabular}{cccccccc}
\hline $\begin{array}{c}\text { Ground } \\
\text { Motion }\end{array}$ & Year & $\begin{array}{c}\text { M } \\
{[\text { SR] }}\end{array}$ & $\begin{array}{c}\text { Vs30 } \\
{[\mathbf{m} / \mathbf{s}]}\end{array}$ & $\begin{array}{c}\text { ASCE 7 } \\
\text { Site Class }\end{array}$ & $\begin{array}{c}\text { Rjb } \\
{[\mathbf{k m}]}\end{array}$ & $\begin{array}{c}\text { Rrup } \\
{[\mathbf{k m}]}\end{array}$ \\
\hline Landers & 1992 & 7.28 & 353.63 & $\mathrm{D}$ & 23.62 & 23.62 \\
Chi-Chi Taiwan & 1999 & 7.62 & 346.56 & $\mathrm{D}$ & 47.67 & 47.67 \\
Loma Prieta & 1989 & 6.93 & 391.91 & $\mathrm{D}$ & 41.71 & 41.88 \\
Imperial Valley & 1979 & 6.53 & 242.05 & $\mathrm{D}$ & 22.03 & 22.03 \\
Northridge & 1994 & 6.69 & 315.57 & $\mathrm{D}$ & 20.11 & 20.72 \\
Kobe & 1999 & 6.9 & 312 & $\mathrm{D}$ & 31.69 & 31.69 \\
San Fernando & 1971 & 6.61 & 316.46 & $\mathrm{D}$ & 22.77 & 22.77 \\
Superstition Hills & 1987 & 6.54 & 179 & $\mathrm{D}$ & 23.85 & 23.85 \\
Tabas Iran & 1978 & 7.35 & 324.57 & $\mathrm{D}$ & 24.07 & 28.79 \\
Kocaeli Turkey & 1999 & 7.51 & 476.62 & $\mathrm{D}$ & 30.73 & 30.73 \\
\hline
\end{tabular}

Ground motion selection procedure has been reviewed before and ground motion scaling for response history analysis need to be discussed. Each ground motion record set consist of two horizontal records and one vertical acceleration record. The vertical record is generally not used for analysis. Pseudo acceleration response spectrum of the ground motions must be scaled to spectral maximum considered eartquake, $\mathrm{MCE}_{\mathrm{R}}$ (Figure 9).

The scaling procedure is applied to a building in Jakarta, Indonesia. The building is in Seismic Design Category D and is situated on Site Class D soils. The site is not within $20 \mathrm{~km}$ of any known fault, so only far-field ground motions are considered. The procedure is applied to the coupled wall structures, which has a period of vibration of $2.764 \mathrm{sec}$ for CWS and $3.033 \mathrm{sec}$ for HCWS. The scaling procedures recomended in ASCE 7-
10 are scaling for $2 \mathrm{D}$ analysis and scaling for 3D analysis. In this study, the scaling procedure is used scaling for 2D analysis. For 2D analysis, the "strongest" components from each ground motion pair, in terms of the peak ground acceleration, are used. The pseudoacceleration response spectra and the average of the spectra for the strongest components required to be scaled such that the average value of the 5\% damped response spectra for the suite of motions is not less than the design response spectrum for the site for periods ranging from $0.2 \mathrm{~T}$ to $1.5 \mathrm{~T}$.

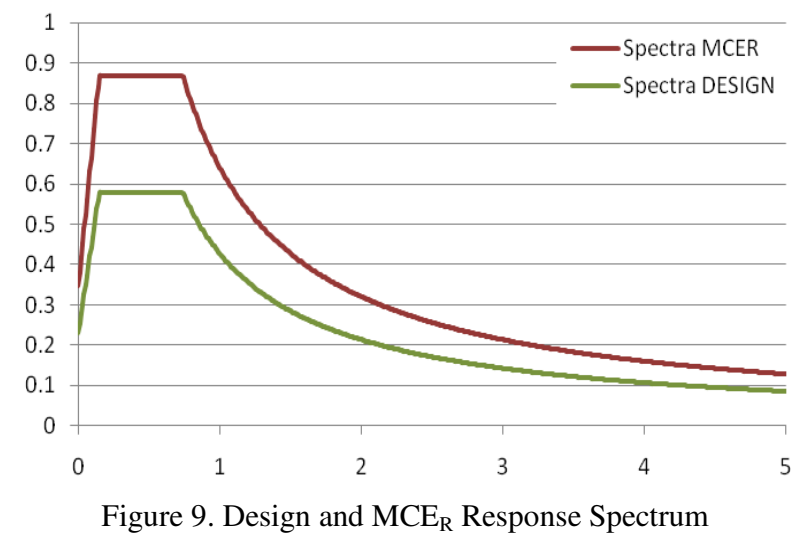

Given that each ground motion has its own scale factor, there are an infinite number of ways to scale the suite of motions. In this study, a two-step scaling approcah is used, which has the advantage of producing a unique set of scale factors for a given ground motions record set. First, scale each ground motion such that it has the same spectral acceleration as the design spectrum at the structure's fundamental period of vibration. This step results in a different scale factor that is FPS-Fundamental Period Scale. A second scale factor, SS-Suite Scale, is applied to each of the fundamental period (FPS) motion and than the average ground motion spectrum scaled to spectral design, MCER, and the average ground motion spectrum falls above the design spectrum at all periods raging from $0.2 \mathrm{~T}$ to $1.5 \mathrm{~T}$. The combined scale factor, SF-Scale Factor, is FPS time SS. The combined scale factor listed in Table 18.

Table 18. Scale Factor for Each Ground Motion

\begin{tabular}{ccccccccc}
\hline Ground & \multirow{2}{*}{\begin{tabular}{c} 
Year \\
\cline { 3 - 8 } Motion
\end{tabular}} & \multicolumn{3}{c}{ FPS } & \multicolumn{3}{c}{ SS } & \multicolumn{3}{c}{ SF = FPS.SS } \\
\hline Landers & 1992 & 1.569 & 1.456 & 1.187 & 1.222 & 1.863 & 1.780 \\
Chi-Chi Taiwan & 1999 & 1.776 & 1.147 & 1.187 & 1.222 & 2.108 & 1.403 \\
Loma Prieta & 1989 & 2.520 & 2.398 & 1.187 & 1.222 & 2.991 & 2.932 \\
Imperial Valley & 1979 & 1.202 & 1.113 & 1.187 & 1.222 & 1.427 & 1.361 \\
Northridge & 1994 & 1.752 & 1.876 & 1.187 & 1.222 & 2.080 & 2.294 \\
Kobe & 1999 & 1.963 & 2.114 & 1.187 & 1.222 & 2.330 & 2.584 \\
San Fernando & 1971 & 2.095 & 1.829 & 1.187 & 1.222 & 2.487 & 2.236 \\
Superstition Hills & 1987 & 0.907 & 0.883 & 1.187 & 1.222 & 1.077 & 1.079 \\
Tabas Iran & 1978 & 3.325 & 2.826 & 1.187 & 1.222 & 3.947 & 3.455 \\
Kocaeli Turkey & 1999 & 2.067 & 2.210 & 1.187 & 1.222 & 2.453 & 2.701 \\
\hline
\end{tabular}




\section{STRUCTURE BEHAVIOR RESPONSES}

In this study, structure behavior analyzed with nonlinier time history analysis, is represented dinamic characteristic of structure system. Structure system design based on SNI2847:2013 and two of coupled wall systems analyzed with performance-based design mehod. Applying a performanced based design approcah, this study design an efficient structure system and produce structure behavior. The analysis structure behavior result are represented by shear structure, coupling structure (CR), element performances objective, and structure or global performance objective.

\section{A. Base Shear}

Base shear of the structure represented lateral resistance of the structure which loaded with lateral forces as ground motions acceleration. Base shear affected by seismic effective mass and stiffnes of the structure. Base shear is made at the base of the wall which role as main element to resisting lateral load. Maximum base shear in each orthogonal horizontal direction are listed in Table 19.

Table 19. Maximum Base Shear at The Base of The Wall

\begin{tabular}{lcccc}
\hline \multirow{2}{*}{ Earthquake } & \multicolumn{2}{c}{ CWS [kN] } & \multicolumn{2}{c}{ HCWS [kN] } \\
\cline { 2 - 5 } San Fernando & X-Dir & Y-Dir & X-Dir & Y-Dir \\
\hline Kobe & 8148.6 & 16966 & 5649.1 & 15244 \\
Northridge & 11490 & 23268 & 12960 & 16664 \\
Imperial Valley & 5370.1 & 13889 & 5187.7 & 14588 \\
Loma Prietta & 5769.5 & 13988 & 5752.6 & 14023 \\
Chi-Chi & 5729.2 & 10991 & 4191.7 & 8563 \\
Landers & 10259 & 20351 & 10052 & 17999 \\
Superstition Hills & 5839.5 & 13336 & 5870.9 & 13285 \\
Tabas & 6604.6 & 15282 & 5851.1 & 14224 \\
Kocaeli & 6314.8 & 11128 & 6594.1 & 11016 \\
\hline Average & 7175.5 & 15730.1 & 6888.32 & 14028.5 \\
\hline
\end{tabular}

In this study, CWS structure as a comparison structure for HCWS structure. Base shear for CWS structure is greater than HCWS structure, which $4 \%(287.18 \mathrm{kN})$ for $\mathrm{x}$-direction and $10.82 \%(1701.6 \mathrm{kN})$ for y-direction. In this case, CWS structure base shear is greater than HCWS caused of seismic effective mass CWS structure also greater than HCWS structure. The seismic effective mass of the CWS structure is greater 385.836 ton than HCWS, which effective mass for CWS is 11845.509 ton and 11459.673 ton for HCWS.

Both of the system structure that loaded by lateral forces, have a structure base shear in $\mathrm{x}$-direction is lower than $y$-direction, and that case indicate lateral resistance greater in $\mathrm{y}$-direction than $\mathrm{x}$-direction. The lateral resistance in $y$-direction only done by reinforced concrete system, whereas coupled wall system and their elements (RC shear walls and coupling beams) resist lateral forces in $\mathrm{x}$-direction, which shear wall have a greater stiffness and strength in y-direction.

\section{B. Coupling Ratio}

The strucutural performance is strongly influenced by the amount of coupling provided by the system. The coupled wall system deformed under the influence of lateral loads, which cause a system overturning moment (OTM). The proportion of OTM resisted by the couple is defined as the Coupling Ratio (CR). The calculation of $\mathrm{CR}$ is also made at the base of the wall when the system form a mechanism. In this idealized case, the coupling beams are assumed to maintain their plastic shear capacity as the wall pier yield. This definition is represented by Table 20 to Table 22 which have a representation of mechanism structure system. The amount of coupling provided by the system is total couple action from each coupling beams entire the height of the structure, and represented by axial forces at the bottom of the wall. In this study, the calculation of coupling ratio was calculated for each ground motion and the average results from each ground motion for produce value of the coupling ratios for respectively system. The value of coupling ratios listed in Table 23 .

Table 20. Mechanism CWS Structure Caused GM in $\mathrm{X}$-Direction

\begin{tabular}{lcccccccc}
\hline & \multicolumn{7}{c}{ First Plastification [sec] } \\
\cline { 2 - 7 } Ground Motion & \multicolumn{7}{c}{ X-Direction } \\
\cline { 2 - 7 } & \multicolumn{7}{c}{ Coupling Beam } & \multicolumn{7}{c}{ Shear Wall } & \\
\cline { 2 - 7 } & CB 100 & CB 75 & CB 50 & P 30 & P 25 & P 20 & \\
\hline Landers'92 & 8.9 & 13.6 & 4.1 & 13.2 & 16.6 & 17.4 & 18.2 \\
Chi-Chi Taiwan'99 & 41.9 & 43.2 & 34.6 & 41.3 & $\Phi$ & $\Phi$ & $\Phi$ \\
Loma Prieta'89 & 4.9 & 5.3 & 4.4 & 4.8 & $\Phi$ & $\Phi$ & $\Phi$ \\
Imperial Valley'79 & 8.6 & 15.4 & 5.6 & 14.9 & $\Phi$ & $\Phi$ & $\Phi$ \\
Northridge'94 & 6.3 & 7.6 & 3.9 & 7.1 & 7.5 & 7.6 & $\Phi$ \\
Kobe'99 & 16.9 & 17.8 & 15.7 & 21.1 & 22.7 & $\Phi$ & $\Phi$ \\
San Fernando'71 & 2.6 & 3.4 & 2.2 & 3.1 & 3.6 & $\Phi$ & $\Phi$ \\
Superstition Hills'87 & 10.2 & 16.7 & 6.5 & 18.4 & $\Phi$ & $\Phi$ & $\Phi$ \\
Tabas Iran'78 & 9.3 & 17 & 2.1 & 19.1 & $\Phi$ & $\Phi$ & $\Phi$ \\
Kocaeli Turkey'99 & 7.3 & 12.9 & 4.3 & 11.8 & $\Phi$ & $\Phi$ & $\Phi$ \\
\hline C
\end{tabular}

$\Phi$ did not yield until the limit time of analysis

Table 21. Mechanism HCWS Structure Caused GM in X-Direction

\begin{tabular}{lcccccccc}
\hline & \multicolumn{7}{c}{ First Plastification [sec] } \\
\cline { 2 - 7 } Ground Motion & \multicolumn{7}{c}{ X-Direction } \\
\cline { 2 - 7 } & \multicolumn{7}{c}{ Coupling Beam } & \multicolumn{7}{c}{ Shear Wall } & \\
\cline { 2 - 7 } & CB 100 & CB 75 & CB 50 & P 30 & P 25 & P 20 & \\
\hline Landers'92 & 8.7 & 13.4 & 2.4 & 13.2 & 16.6 & 17.4 & 18.3 \\
Chi-Chi Taiwan'99 & 35.1 & 41.6 & 22.4 & 47.3 & $\Phi$ & $\Phi$ & $\Phi$ \\
Loma Prieta'89 & 4.1 & 4.9 & 2.3 & 4.9 & $\Phi$ & $\Phi$ & $\Phi$ \\
Imperial Valley'79 & 7.4 & 8.9 & 2.1 & 15.2 & $\Phi$ & $\Phi$ & $\Phi$ \\
Northridge'94 & 3.2 & 3.9 & 1.6 & 6.6 & 7 & 7.4 & $\Phi$ \\
Kobe'99 & 15.7 & 17.1 & 10.3 & 21.8 & $\Phi$ & $\Phi$ & $\Phi$ \\
San Fernando'71 & 2.4 & 3.6 & 1.5 & 3.1 & 5.4 & $\Phi$ & $\Phi$ \\
Superstition Hills'87 & 6.8 & 8.4 & 5.2 & 18.5 & $\Phi$ & $\Phi$ & $\Phi$ \\
Tabas Iran'78 & 3.4 & 8.9 & 1.7 & 19.1 & $\Phi$ & $\Phi$ & $\Phi$ \\
Kocaeli Turkey'99 & 7.5 & 13.5 & 2.3 & 10.7 & 12.2 & $\Phi$ & $\Phi$ \\
\hline
\end{tabular}

$\Phi$ did not yield until the limit time of analysis 
Table 22. Mechanism CWS and HCWS Structure Caused GM in Y-Direction

\begin{tabular}{lccccccc}
\hline & \multicolumn{3}{c}{ Firt Plastification Shear Wall[sec] } \\
\cline { 2 - 7 } \multicolumn{1}{c}{ Ground Motion } & \multicolumn{3}{c}{ CWS } & \multicolumn{4}{c}{ HCWS } \\
\cline { 2 - 7 } & P 30 & P 25 & P 20 & P 30 & P 25 & P 20 \\
\hline Landers'92 & 13.2 & 15.4 & 16.9 & 13.2 & 15.4 & 16.9 \\
Chi-Chi Taiwan'99 & 41.4 & $\Phi$ & $\Phi$ & 44.2 & $\Phi$ & $\Phi$ \\
Loma Prieta'89 & 4.7 & 10.1 & $\Phi$ & 4.7 & 10.1 & $\Phi$ \\
Imperial Valley'79 & 8.3 & 20 & $\Phi$ & 8.3 & 20 & $\Phi$ \\
Northridge'94 & 6.3 & 6.7 & 7.1 & 5.2 & 6.6 & 7.2 \\
Kobe'99 & 16.8 & 20.2 & 22.4 & 16.9 & 22.2 & $\Phi$ \\
San Fernando'71 & 2 & 2.1 & 4.7 & 2.1 & 3.6 & 4.7 \\
Superstition Hills'87 & 14.4 & 14.8 & $\Phi$ & 14.4 & 14.8 & $\Phi$ \\
Tabas Iran'78 & 11 & 20.5 & 22.4 & 11.1 & 22 & $\Phi$ \\
Kocaeli Turkey'99 & 8.4 & 13 & $\Phi$ & 7.1 & 11.6 & $\Phi$ \\
\hline Ф did not yield until the limit time of analysis
\end{tabular}

Table 23. Coupling Ratio of The Structure System

\begin{tabular}{lcc}
\hline \multicolumn{1}{c}{ GM } & CR CWS & CR HCWS \\
& \% & \% \\
\hline San Fernando & 66.15 & 66.05 \\
Kobe & 72.62 & 66.50 \\
Northridge & 61.40 & 56.52 \\
Imperial Valley & 63.56 & 64.13 \\
Loma Prietta & 64.66 & 64.56 \\
Chi-Chi & 65.42 & 72.69 \\
Landers & 58.36 & 58.57 \\
Superstition Hills & 69.68 & 69.35 \\
Tabas & 66.23 & 66.81 \\
Kocaeli & 64.54 & 60.29 \\
\hline Average & 65.26 & 64.55 \\
\hline
\end{tabular}

In this study, the 25-storey reinforced concrete structure with three types of walls and beams, having CR values $65.26 \%$ and $64.55 \%$. Value of the coupling ratios represent that couple action in both of the system resist $0.65(65 \%)$ the imposed overturning moments-OTM, while the remaining of the resistance to the OTM is provided by individual wall pier moment reactions. CR value of the CWS structure is greater $0.71 \%$ than HCWS structure, and that values in line RC coupling beams has couple action greater than steel coupling beams. The base shear is represented by couple action, which CWS structure has a greater base shear and so coupled action than HCWS structure.

The forgoing discussion indicates that various researchers have successfully utilized a wide range of coupling ratios. The $\mathrm{CR}$ values from this study represent an efficient design for the stuctures and meet an upper limit to ensure sound satiesfied all structural performance criteria. Based on this result of the study, the structure having high CR values, $\mathrm{CR}>60 \%$, has more widespread cracking in the upper portions of the wall piers and suffered earlier crushing failure of the wall. The widespread cracking of the wall can be seen in Table 20 to Table 22, which had a plastification in the upper portions of the wall piers (P25 and P20). In this study, according with the used assumption, the coupling beams are maintain their plastic shear capacity as the wall piers yield. This mechanism shows by plastification at the coupling beam and follows by plastification at the bottom of the wall and the upper section of the wall. Structure behavior performance of the structure represented by failure mechanism, which start with plastification in all coupling and follow with plastification at the bottom of the wall.

\section{Element Performaces}

Element performances represent the overall structure behavior. In the most building code apllications, the desired performance of a structure is that it will statisfy Life Safety (LS) requierments at the design level earthquake (conventionally defined as having a $10 \%$ probability of exccedance in 50 years (10/50)) and Collapse Prevention $(\mathrm{CP})$ requirements at the maximum credible event (2\% in 50years $(2 / 50))$. The code building, ASCE/SEI41-13 provides table for acceptance criteria for common strucutral system and their elements. The acceptance criteria for coupling beams in Table 24, based upon plastic rotation angle. Objective performance of the elements structure in every story level, which the average result from NLTHA is listed in Table 25. Both objective performances of the coupling beams based on maximum plastic hinge rotation which result from respectively ground motion is listed in Table 26.

For the two types of coupling beams, objective performance of the coupling beams based on Table 24, (ASCE/SEI 41-13) had a range in LS to CP. Three types of reinforced concrete coupling beams have their own objective performance. Performance objective of the coupling beam type CB 100 is at LS level, which is maximum plastic hinge ratio is $-0.01 \mathrm{rad}$ that in the range 0.006 to $0.03 \mathrm{rad}$. For coupling beam type $\mathrm{CB} 75$, the objective performance is at $\mathrm{CP}$ level with maximum plastic hinge rotation is $-0.034 \mathrm{rad}$ and between 0.03 to $0.05 \mathrm{rad}$. For the last type of RC coupling beam, CB 50, is at LS level with maximum plastic hinge rotation is $0.016 \mathrm{rad}$ and at range 0.5 to $0.02 \mathrm{rad}$. Similiarly result for the other type of coupling beams, steel coupling beams, objective performance is at range LS to CP level. Performance objective of three type of steel coupling beams are LS for IWF 700X300, CP for IWF 600X200, and LS for IWF 200X200, with the average respectively maximum plastic hinge ratio $-0.028 \mathrm{rad},-0.086 \mathrm{rad}$, and $0.014 \mathrm{rad}$

Table 24. Acceptance Criteria for Coupling Beams

\begin{tabular}{cccc}
\hline \multirow{2}{*}{ Beam Type } & \multicolumn{3}{c}{ Plastic Hinge Rotation } \\
\cline { 2 - 4 } & IO & LS & CP \\
\hline CB 500X1000 & 0.006 & 0.030 & 0.050 \\
CB 400X750 & 0.006 & 0.030 & 0.050 \\
CB 300X500 & 0.005 & 0.020 & 0.040 \\
IWF 700X300X13X24 & 0.0083 & 0.0993 & 0.1324 \\
IWF 600X200X11X17 & 0.0071 & 0.0848 & 0.1131 \\
IWF 200X200X8X12 & 0.0024 & 0.0289 & 0.0385 \\
\hline
\end{tabular}


Table 25. Objective Performances of The Coupling Beam at Story Level

\begin{tabular}{|c|c|c|c|c|}
\hline \multirow{2}{*}{ Storey } & \multicolumn{2}{|c|}{ Plastic Hinge Rotation } & \multicolumn{2}{|c|}{ Objective Performance } \\
\hline & CWS & HCWS & CWS & HCWS \\
\hline 25 & -0.016 & -0.014 & LS & LS \\
\hline 24 & -0.015 & -0.013 & LS & LS \\
\hline 23 & -0.016 & -0.014 & LS & LS \\
\hline 22 & -0.016 & -0.014 & LS & LS \\
\hline 21 & -0.016 & -0.014 & LS & LS \\
\hline 20 & -0.034 & -0.086 & $\mathrm{CP}$ & $\mathrm{CP}$ \\
\hline 19 & -0.034 & -0.086 & $\mathrm{CP}$ & $\mathrm{CP}$ \\
\hline 18 & -0.033 & -0.085 & $\mathrm{CP}$ & $\mathrm{CP}$ \\
\hline 17 & -0.033 & -0.085 & $\mathrm{CP}$ & $\mathrm{CP}$ \\
\hline 16 & -0.033 & -0.084 & $\mathrm{CP}$ & LS \\
\hline 15 & -0.033 & -0.084 & $\mathrm{CP}$ & LS \\
\hline 14 & -0.033 & -0.083 & $\mathrm{CP}$ & LS \\
\hline 13 & -0.033 & -0.083 & $\mathrm{CP}$ & LS \\
\hline 12 & -0.033 & -0.082 & $\mathrm{CP}$ & LS \\
\hline 11 & -0.033 & -0.082 & $\mathrm{CP}$ & LS \\
\hline 10 & -0.010 & -0.028 & LS & LS \\
\hline 9 & -0.010 & -0.028 & LS & LS \\
\hline 8 & -0.010 & -0.027 & LS & LS \\
\hline 7 & -0.010 & -0.027 & LS & LS \\
\hline 6 & -0.009 & -0.027 & LS & LS \\
\hline 5 & -0.009 & -0.027 & LS & LS \\
\hline 4 & -0.009 & -0.026 & LS & LS \\
\hline 3 & -0.009 & -0.026 & LS & LS \\
\hline 2 & -0.009 & -0.024 & LS & LS \\
\hline 1 & -0.009 & -0.024 & LS & LS \\
\hline
\end{tabular}

Table 26. Objective Performances of The Coupling Beam

\begin{tabular}{ccccc}
\hline \multirow{2}{*}{ Type } & \multicolumn{2}{c}{ Plastic Hinge Rotation } & \multicolumn{2}{c}{ Objective Performance } \\
\cline { 2 - 5 } & CWS & HCWS & CWS & HCWS \\
\hline Deep CB & -0.010 & -0.028 & LS & LS \\
Medium CB & -0.034 & -0.086 & CP & CP \\
Short CB & -0.016 & -0.014 & LS & LS \\
\hline
\end{tabular}

The design of two types of coupling beam exhibiting a good behavior and satisfying all performance criteria. Coupling beams with low aspect ratio $(\ln / \mathrm{h} \leq 2)$, deep coupling beam, have performed in LS level. Whereas coupling beams with aspect ratio between 2 and 4 $(2<\ln / \mathrm{h}<4)$ performed at CP level, and coupling beams with high aspect ratio $(\ln / \mathrm{h} \geq 4)$ performed in LS level. The steel coupling beams with aspect ratio $2<\ln / \mathrm{h}<4$ have a better performance than reinforced concrete at 11 to 16 story, and the two of coupling beams with low and high aspect ratio for both structure system have a same objective performance.

\section{Global Performances}

Obejctive performance of the structure not only judge from their elements objective performance but also based on structure drift. In building code ATC40:1996, their provide table for acceptance criteria (Table 28). Two dinamic behavior of the structure that used to determine structure obejective performace, are interstory drift ratio and roof drift ratio.

Table 28. Accpetance Criterian Based on ATC40:1996

\begin{tabular}{lcccc}
\hline \multirow{2}{*}{ Parameter } & \multicolumn{4}{c}{ Objective Performace } \\
\cline { 2 - 5 } & $\begin{array}{c}\text { Immediate } \\
\text { Occupancy }\end{array}$ & $\begin{array}{c}\text { Damage } \\
\text { Control }\end{array}$ & $\begin{array}{c}\text { Life } \\
\text { Safety }\end{array}$ & $\begin{array}{c}\text { Collapse } \\
\text { Prevention }\end{array}$ \\
\hline Interstory Drift & 0.01 & $0.01-0.02$ & 0.02 & $0.33(\mathrm{Vi} / \mathrm{Pi})$ \\
Roof Drift & 0.005 & - & 0.01 & 0.02 \\
\hline * Vi is Story shear and Pi is Ultimate axial load
\end{tabular}

Interstory drift ratio is ratio between drift at the story level with drift at below the story level. SNI 1726:2012 provisions limit the interstory drift to $2 \%$ of the story height. Analysis results composed by minimum and maximum drift value and will be reviewed based on Table 28. The positive and negative envelopes of maximum observed interstory drifts for two buildings for the suite of the earthquakes are shown in Figure 11 to 14.

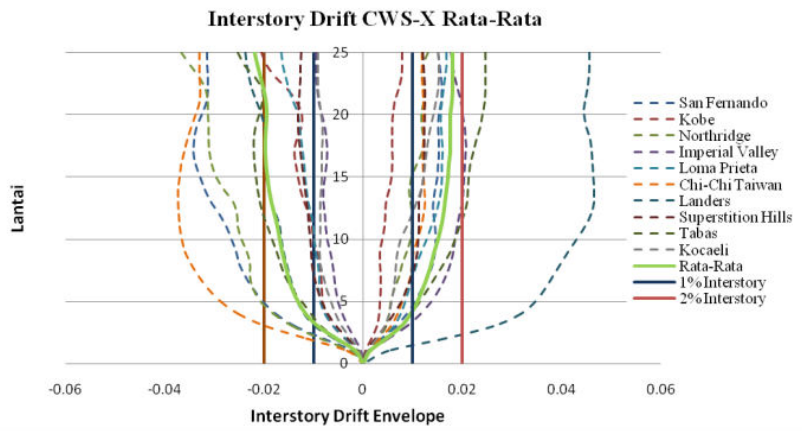

Figure 11. Interstory Drift Ratio Envelopes for The CWS Structure in X-Direction Interstory Drift CW S-Y Rata-Rata

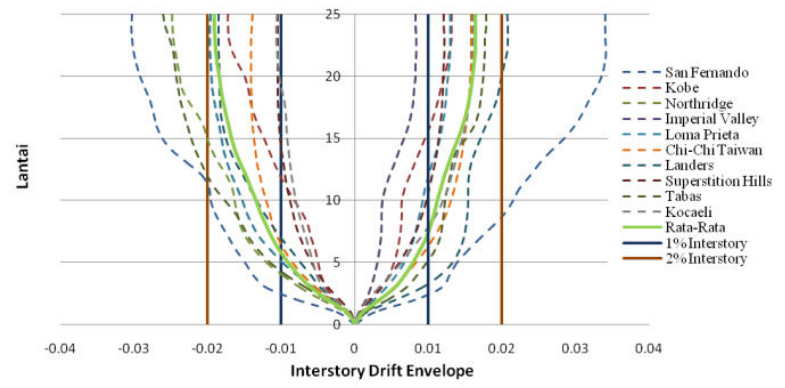

Figure 12. Interstory Drift Ratio Envelopes for The CWS Structure in Y-Direction

Interstory Drift HCWS-X Rata-Rata

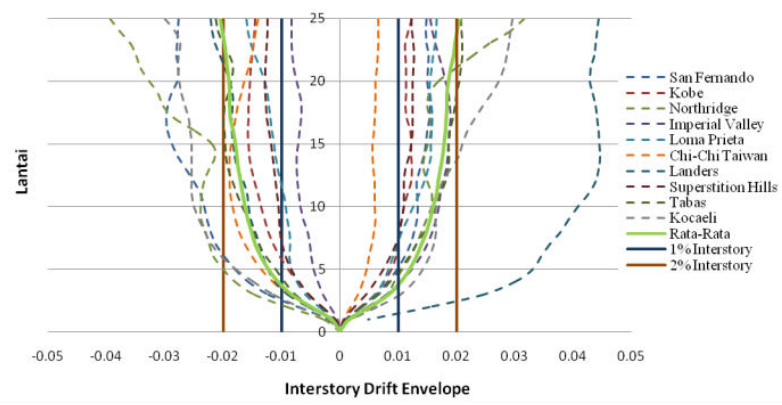

Figure 13. Interstory Drift Ratio Envelopes for The HCWS Structure in X-Direction 


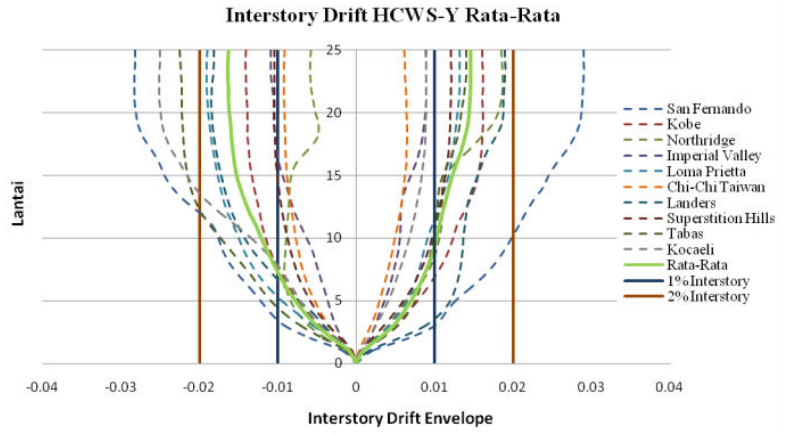

Figure 14. Interstory Drift Ratio Envelopes for The HCWS Structure in Y-Direction

For some ground motions like Loma Prieta, Kobe Japan, Kocaeli Turkey, and Superstition Hills, the CWS structure satisfied the $2 \%$ drift limit and the other exceed the $2 \%$ limit. On the other hand, for ground motions like Landers, San Fernando, Northridge, Tabas Iran, and Kocaelli Turkey, the interstory drift of HCWS structure exceed the $2 \%$ drift limit.

In this study, the average value of interstory drift was use in NLTHA, which the analysis use ten pairs of ground motion. The average value for interstory drift ratio in $\mathrm{x}$-direction only marginally exceeded the $2 \%$ limit, therefore both of structure, CWS and HCWS, have performed at LS level. For the average value for interstory drift ratio in y-direction satisfied the $2 \%$ drift limit for both structure. Structure obejctive performance is at Life Safety-LS level in respectively direction. Where, in this level objective performance, structural damage and non-structural damage, were happen. However, interstory drift envelopes reflect the severity of ground motion considered. Interstory drift envelopes in $\mathrm{x}$-direction greater than $\mathrm{y}$-direction and that things show if the severity of ground motion have a lower effect in ydirection than the other orthogonal direction.

Roof drift ratio is another parameter can be used to describe structure objective performance besides interstory drift ratio. Roof drift ratio is ratio between drift at the top structure to the story height. Analysis results composed by minimum and maximum drift value and will be reviewed based on Table 26. The positive and negative of maximum observed roof drift ratio for two buildings for the suite of the earthquakes are listed in Table 27 and Table 28 and shown in Figure 14 to 17.

Some ground motions like San Fernando, Chi-Chi Taiwan, and Landers, the CWS strcuture exceed the 1\% drift limit and performe at Collapse Prevention-CP level. The other ground motions shown the structure behavior is at Life Safety-LS objective performance. The HCWS stucture behavior under San Fernando and Landers ground motions produced objective performance at Collapse Prevention-CP level, and the other perform at Life Safety-LS level.

The overall building high is $87.5 \mathrm{~m}$, thus the 0.005 and 0.01 drift limits are $0.438 \mathrm{~m}$ and $0.875 \mathrm{~m}$, respectively. Based on roof drift ratio, objective performance for both structure CWS and HCWS are at Life Safety-LS for respectively horizontal direction. The positive and negative value of history roof drift ratio of the CWS structurre are -0.007 in $\mathrm{x}$-direction and -0.006 in $\mathrm{y}$ direction, which roof drift ratio is at between 0.005 and
0.01. Roof drift ratio for CWS structure in $\mathrm{x}$-dir lower than HCWS and inversely proportional in y-dir.

Table 27. Objective Performance Based on Roof Drift Ratio in CWS Structure

\begin{tabular}{lcccc}
\hline \multirow{2}{*}{ Ground Motion } & \multicolumn{4}{c}{ Roof Drift Ratio } \\
\cline { 2 - 6 } Xan Fernando & 0.005 & -0.012 & 0.011 & -0.010 \\
Kobe & 0.001 & -0.004 & 0.004 & -0.005 \\
Northridge & 0.003 & -0.009 & 0.002 & -0.008 \\
Imperial Valley & 0.008 & -0.003 & 0.002 & -0.003 \\
Loma Prietta & 0.006 & -0.004 & 0.005 & -0.007 \\
Chi-Chi & 0.005 & -0.015 & 0.006 & -0.006 \\
Landers & 0.020 & -0.007 & 0.007 & -0.007 \\
Superstition Hills & 0.004 & -0.005 & 0.005 & -0.004 \\
Tabas & 0.008 & -0.008 & 0.006 & -0.009 \\
Kocaeli & 0.004 & -0.003 & 0.006 & -0.004 \\
AVERAGE & 0.006 & -0.007 & 0.005 & -0.006 \\
\hline \multicolumn{1}{c}{$\quad$ Objective } & LS & LS & LS & LS \\
\multicolumn{1}{c}{ Performance } & & & & \\
\hline
\end{tabular}

Table 28. Objective Performance Based on Roof Drift Ratio in HCWS Structure

\begin{tabular}{lcccc}
\hline \multirow{2}{*}{ Ground Motion } & \multicolumn{4}{c}{ Roof Drift Ratio } \\
\cline { 2 - 6 } X-Dir & \multicolumn{2}{c}{ Y-Dir } \\
\hline San Fernando & 0.005 & -0.011 & 0.010 & -0.009 \\
Kobe & 0.004 & -0.006 & 0.006 & -0.005 \\
Northridge & 0.004 & -0.008 & 0.004 & -0.002 \\
Imperial Valley & 0.007 & -0.003 & 0.002 & -0.003 \\
Loma Prietta & 0.006 & -0.004 & 0.005 & -0.007 \\
Chi-Chi & 0.002 & -0.007 & 0.002 & -0.004 \\
Landers & 0.018 & -0.006 & 0.006 & -0.007 \\
Superstition Hills & 0.004 & -0.005 & 0.005 & -0.004 \\
Tabas & 0.007 & -0.007 & 0.005 & -0.008 \\
Kocaeli & 0.008 & -0.010 & 0.003 & -0.008 \\
AVERAGE & 0.007 & -0.007 & 0.005 & -0.006 \\
\hline \multicolumn{1}{c}{$\quad$ Objective } & \multirow{2}{*}{ LS } & LS & IO & LS \\
\multicolumn{1}{c}{ Performance } & & & & \\
\hline
\end{tabular}

\section{CONCLUSION}

1. The couple action in CWS structure is greater than HCWS structure, that represented by the value of coupling ratio $(\mathrm{CR})$ of the structure, where in this study, reinforced concrete structure with three types of walls and beams, having CR values $65.26 \%$ and $64.55 \%$. Value of the coupling ratios represent that couple action in both of the system resist $0.65(65 \%)$ the imposed overturning moments-OTM, while the remaining of the resistance to the OTM is provided by individual wall pier moment reactions.

2. Failure mechanism of both structure system design with the assumption coupling beam plastification at the entire height of structure and followed by yielding at the bottom of wall pier is achieved.

3. Based on this result of the study, the structure has high $\mathrm{CR}$ values, $\mathrm{CR}>60 \%$, has more widespread cracking in the upper portions of the wall piers and suffered earlier crushing failure of the wall.

4. Structure objective performance, based on their elements behavior and analized by the suite of the maximum earthquake $\left(\mathrm{MCE}_{\mathrm{R}}\right)$, is at Collapse 
prevention-CP with plastic hinge rotation exceed the rotation limit from ASCE/SEI41-13.

5. Based on ATC 40:1996, the two parameters used to get global performances, are interstory drift ratio and roof drift ratio. The average value for interstory drift ratio only marginally exceeded the $2 \%$ limit in $\mathrm{x}$ direction and not exceed the $2 \%$ drift limits in $y$ direction, perform at Life Safety-LS level of the objective performance. Based on roof drift ratio, both of structure system behavior perform at Life SafetyLS with drift ratio between 0.005 to 0.01 .

6. Although the building is in Seismic Design Category $\mathrm{D}$ and the height of the structure exceeds the requirement from SNI1726:2012, a design exhibiting good behavior and satisfied all performance criteria.

7. The steel coupling beam can be an alternative for RC coupling beam which has a complex and and unefficient detailing construction. Which, behavior of the HCWS structure as good as CWS structure.

\section{REFERENCES}

[1] Abdalla Eljadei, Abdelateee (2012), "Performance Based Design of Coupled Wall Structures", Doctor. Disertation, Faculty of Swanson School of Engineering.

[2] ACI Committee 318M .(2011). Building Code Requirements for Structural Concrete (ACI 318M-2011) and Commentary (ACI 318R-2011), American Concrete Institute, Farmington Hills, MI, 443 pp.

[3] AISC: ANSI/AISC 341-10, Seismic Provision for Structural Steel Buildings. (2010). Seismic Provisions for Structural Steel Buildings. American Institute of Steel Construction Committee on Spesifications, Chicago, Illinois.

[4] AISC: ANSI/AISC 360-10, Spesification for Structural Buildings. (2010). Spesification for Structural Buildings. American Institute of Steel Construction Committee on Spesifications, Chicago, Illinois.

[5] ASCE: FEMA 356, Prestandard and Commentary for The Seismic Rehabilitation of Buildings. (2000). American Society of Civil Engineers. Federal Emergency Management Agency, Washington D.C.

[6] ASCE/SEI 41-13, Seismic Evaluation and Retrofit Existing Buildings. (2013). American Society of Civil Engineers. Structural Engineering Institute, Virginia. Binney, J. R. (1972), "Diagonally Reinforced Coupling Beams", Master. Thesis, University of Caterbury, Christchurch, New Zealend.

[7] Dr. H. Powell,Graham. A Presentation of Computers \& Structures. Performance Based Design Using Nonlinear Analysis PERFORM 3D. Computer and Structures, Inc. University of California. Berkley.
[8] Draft ASCE Composite Construction Committee: version 8, Recomendations for Seismic Design of Hybrid Coupled Walls. American Society of Civil Engineers Structural Engineering Institute, Sherif El-Tawil, Ph: 7347645617.

[9] Hassan, M. (2004), "Inelastic Dynamic Behaviour and Design of Hybrid Coupled Wall System", Doctor. Dissertation, University of Central Florida.

[10] Lu, Xilin dan Chen, Yuntao. (2005), "Modelling of Coupled Shear Wall and Its Experimental Verification", Journal of Structural Engineering ASCE.

[11] N. Lowes, Laura and Friends. Behavior, Analysis, and Design of Complex Wall System. Coupled Wall Test Program Summary Document. (2011). Research on coupled wall CW1, University of Washington and University of Illinois, Urbana-Champaign.

[12] Naish, David. and Friends. (2013)," Reinforced Concrete Coupling Beams-Part II:Modeling”, ACI Structural Journal. 110-S87.

[13] Paulay, T. (1969), " The Coupling of Shear Walls", Doctor. Thesis, University of Caterbury, Christchurch, New Zealend.

[14] Paulay, T. (1971), “ Coupling Beams of Reinforced Concrete Shear Walls", Journal of the Structural Division, ASCE, V.97, No.3, pp. 843-862.

[15] PERFORM 3D Program Documentation: ISO PER053111M3. (2011). Components and Elements. CSI Computer and Stuctures INC., Barkley California, USA.

[16] RSNI 1729.2: ICS, Ketentuan desain tahan gempa untuk struktur gedung baja. (2011), Badan Standarisasi Nasional, Indonesia.

[17] Santhakumar, A.R. (1974), " The Ductility of Coupled Shear Wall", Doctor. Thesis, University of Caterbury, Christchurch, New Zealend.

[18] SNI 1726: ICS 91.120.25;91.080.01, Tata cara perencanaan ketahanan gempa untuk struktur bangunan gedung dan non gedung. (2012), Badan Standarisasi Nasional, Indonesia.

[19] SNI 1729: ICS 91.080.10, Spesifikasi untuk bangunan gedung baja struktural. (2015), Badan Standarisasi Nasional, Indonesia.

[20] SNI 2847: ICS 91.080.40, Persyaratan beton struktural untuk bangunan gedung. (2013), Badan Standarisasi Nasional, Indonesia.

[21] Wan-Shin, Park., dan Hyun Do, Yun. (2005), "The Bearing Strength of Steel Coupling Beam-Reinforced Concrete Shear Wall Connections", Nuclear Engineering and Design Journal, 236(2006), 77-93.

[22] Wijaya, Anita. (2012), "Evaluasi Kinerja Struktur Portal Beton Bertulang dengan Dinding Geser Berdasarkan RSNI-03-1726-201x", Fakultas Teknik Program Studi teknik Sipil. Universitas Katolik Parahyangan.

[23] Xuan, Gang. (2005), "Performance Based Design of a 15 Story Reinforced Concrete Coupled Core Wall Structure", Master. Thesis, University of Cincinnati 